\title{
Marignac and Jørgensen: Two Forgotten Inorganic Explorers
}

\author{
Alan F. Williams*
}

\begin{abstract}
The lives and contributions of Jean-Charles Galissard de Marignac (1817-1894) and Christian Klixbüll Jørgensen (1931-2001) are reviewed briefly.
\end{abstract}

Keywords: Inorganic chemistry · Jørgensen, C. K. · Marignac, J.-C. G. · University of Geneva

For many years the University of Geneva had a chair of inorganic and organic chemistry: the post would have been better described as inorganic or organic chemistry with the second usually predominating. There have been however two major figures in inorganic chemistry in Geneva, Jean-Charles Galissard de Marignac (1817-1894) and Christian Klixbüll Jørgensen (1931-2001). Both were recognised internationally as major figures in their time; neither left a large school of pupils to maintain the reputation of their master, and consequently their contributions have tended to be forgotten in recent years. This paper will review briefly their lives and contributions to inorganic chemistry.

Jean-Charles Galissard de Marignac was born in Geneva on 24th April 1817. His family came originally from Languedoc, and, as protestants, had sought refuge in Geneva after the revocation of the Edict of Nantes, becoming bourgeois of Geneva in 1733. Marignac's father Jacob was successively a judge and a member of the cantonal government (conseiller d'Etat) and his mother was the sister of Augustin Le Royer, whose pharmacy was a centre of Geneva's scientific life. After studying at the Académie de Genève (later to become the Université) he entered the Ecole Poly-

\footnotetext{
${ }^{*}$ Correspondence: Prof. A. F. Williams

Department of Inorganic, Analytical and Applied Chemistry

Université de Genève

30 quai Ernest-Ansermet

$\mathrm{CH}-1211$ Geneva

Tel.: +4122 3796425

Fax: +41223796830

E-mail: alan.williams@unige.ch
}

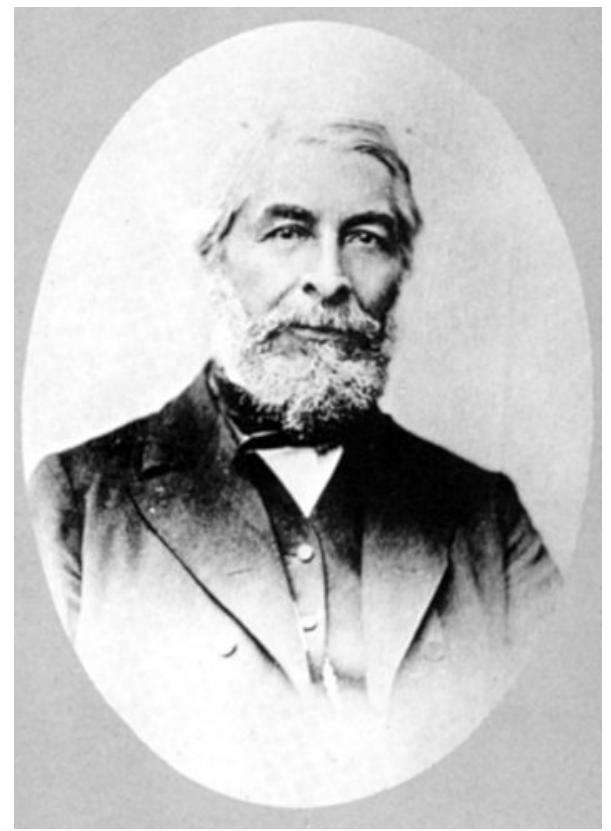

Jean-Charles Galissard de Marignac

technique in Paris in 1835 and graduated two years later as first of his promotion. He then moved to the Ecole de Mines where he spent two years during which he travelled extensively, visiting Berzelius, Liebig and Wohler. In 1840 he spent six months in Giessen with Liebig before being appointed to the porcelain factory of Sèvres. Although he seemed to be set on course for a brilliant career in the French administration, he accepted a call from the Académie in Geneva to become professor of chemistry in 1841, and was appointed professor of mineralogy in 1845. This appointment could not be regarded as a good career move. The salary was extremely modest, the laboratory was situated in the basement, dark and humid, and he had to buy much of his equipment with his own means. In 1873 the Académie became the Université and a new school of chemistry was built (still visible at the head of the Boulevard des Philosophes). In 1878 he resigned from his chair for health reasons.
He established a small laboratory in his house in the rue Senebier, and continued his work, but his health continued to decline, and his last publication appeared in 1887. He died just before his 77 th birthday on 15th April 1894.

Marignac's major contribution was in the separation of chemical elements and the accurate determination of atomic weights. To evaluate his contribution fairly we must realise the state of chemistry when he began his career. Dalton's atomic theory had been more or less accepted, and Berzelius had developed the modern system of nomenclature to describe composition, superseding the rather complicated hieroglyphics of Dalton. Mendeleyev's periodic table was still 25 years in the future, and indeed would depend on reliable atomic weights and correct stoichiometries for its elaboration. The discovery of new chemical elements was very much a random affair: of course many elements were undiscovered, but it is often forgotten that many non-existent elements had been claimed to be discovered. The element with $Z=43$ was 'discovered' seven times before Perrier and Segrè isolated technetium from a sample of metal irradiated in Lawrence's cyclotron, and this is a favourable case in as much as the element does actually exist. Most new elements were discovered in minerals, and required considerable expertise in extraction and separation. The atomic weight represented an essential parameter for the characterisation of any new element.

After Marignac's first papers on atomic weights (silver, potassium and chlorine in 1842), Berzelius wrote to him a letter of encouragement, saying "I put the highest value on your experiments concerning atomic weights; the patience with which you repeat each experiment many times, the wisdom with which you vary your methods and the conscientious way in which you quote the figures given by the balance will ensure you the full confidence of chemists." He continues by 
asking Marignac to pursue this work of determination of atomic weights, underlining its importance, and saying that he knows of no-one better suited to carry it out. Marignac determined atomic weights for 28 elements, and may be considered to have more than satisfied Berzelius' hopes.

For separation of elements the main techniques used were solubility in acid or base, and crystallisation. The study of crystals was thus a central technique and Marignac's papers are full of careful drawings of crystal form and measurements of interfacial angles. This was also important to establish isomorphism of different compounds, and, following Misterlich, to deduce the similarity of their composition. Marignac's work on silicon and zirconium is a good example: he obtained fluorometallate salts by fusion with $\mathrm{KHF}_{2}$. These crystallised nicely, enabling their purification, and proved to be isomorphous with the known fluorostannate salts. This allowed him to establish the formula of quartz as $\mathrm{SiO}_{2}$, a central question since when he carried out this work in $1858^{[1]}$ it was also described in the literature as $\mathrm{SiO}, \mathrm{Si}_{2} \mathrm{O}_{3}$ and $\mathrm{SiO}_{3}$. After much careful work he was able to develop the fluoride fusion method to allow the separation of niobium and tantalum as $\mathrm{K}_{3} \mathrm{NbOF}_{6}$ (soluble) and $\mathrm{K}_{2} \mathrm{TaF}_{7}$ (slightly soluble). This allowed for the first time the separation of the two elements ${ }^{[2]}$ and the isolation of a sample of niobium metal. It also saw off a number of non-existent elements such as ilmenium which were mixtures of niobium and tantalum. He then extended this work to tungsten, and published careful work on the tungstic acids, including the synthesis and analysis of silicotungstic acid, $\mathrm{H}_{4}\left[\mathrm{SiW}_{12} \mathrm{O}_{40}\right] \cdot 29 \mathrm{H}_{2} \mathrm{O}$ and related compounds. ${ }^{[3]}$ Even today this is difficult chemistry: in the middle of the 19th century it was a remarkable achievement.

Marignac was involved in the controversy over the relative merits of atomic and equivalent weights of elements. As he pointed out, the equivalent weight is easy to measure, but difficult to define, whereas an atomic weight may easily be defined but is difficult to measure. To a modern chemist such arguments are prehistoric but in the 1850s were the subject of lively debate. Marignac set great store by the concordance of many observations, including isomorphism, specific heat (using Dulong and Petit's law) and where applicable, Avogadro's hypothesis. Unfortunately there were well known exceptions to both Dulong and Petit's law and Avogadro's hypothesis. The vapour density of ammonium chloride for example was half what it should be: Marignac's investigation of this is interesting. He showed that the latent heat of vaporisation of this compound was much higher than the latent heat of other simple liquids, and that it was close to the enthalpy change when hydrogen chloride gas reacted with ammonia, thereby establishing that the vaporisation involved dissociation, and explaining the low density.

A final field of activity, and probably that for which he is best known, was in rare earth chemistry. His first paper dates already from 1848 where he describes the separation of lanthanum, cerium and didymium (the name given to a mixture of neodymium and praseodymium, only separated much later by Auer von Welsbach).



Crystallography in the 19th century: Marignac's drawings of crystals of $\mathrm{K}_{2} \mathrm{SbF}_{7} \cdot 2 \mathrm{H}_{2} \mathrm{O}(\mathbf{1}, 2$ and 3) and $\left(\mathrm{NH}_{4}\right)_{2} \mathrm{SbF}_{7}$. $\mathrm{H}_{2} \mathrm{O}(4)$
Five years later he redetermined the equivalent weight of didymium, obtaining an equivalent weight from the oxide close to that for praseodymium. At that time he believed the metals to be bivalent, but corrected this later in 1874. In 1878 reported his studies of a large sample of gadolinite: he spent some two years separating the different elements present, usually by thermal decomposition of the nitrates. Interestingly he now used the absorption spectrum to follow the progress of the separation, in collaboration with Louis Soret who was professor of physics. He separated the yttrium and erbium present as well as a yellow compound which he attributed to terbium. He continued this work, examining the erbium containing fraction, and isolated a new element which he named ytterbium, although von Welsbach later showed it to contain lutecium as well. The atomic weight he reported was 172.5 compared with the modern value of 173.04 . In 1880 he reported studies on samarskite from North America which he separated by using the different solubilities of the sulphates. The progress of the separation was determined from the solubilities and from the observed equivalent weight. It was in the course of this work that he isolated the first gadolinium compounds. He is now generally credited with the discovery of ytterbium and gadolinium, the only elements to have been discovered in Switzerland. He recognised the possible existence of other elements in his samples, but had insufficient material to carry his investigations further.

Marignac carried out much other work of interest: an elegant series of experiments in which he showed that ozone contains only oxygen, and he was an early champion of the idea that ozone was merely an allotrope of oxygen, finally established as $\mathrm{O}_{3}$ by Soret's measurement of its vapour density. As professor of mineralogy he carried out many crystallographic analyses of minerals and simple compounds, and made numerous measurements of the specific heats of solutions. Among his more spectacular experiments was the repetition of Foucault's pendulum experiment in the cathedral of St Pierre in Geneva, carried out with Guillaume Dufour and Wartmann in 1851. Among his final works was a study of the concentration of organic matter in the Rhône, to establish whether the municipal water supply was contaminated by drains emptying into the river.

Marignac's personality is difficult to describe. He worked quite alone in his laboratory, taking only some bread to eat in the middle of the day. He appears to have combined modesty with shyness. He refused to be rector of the university and discouraged friends who sought his nomination to the Legion d'Honneur. As he grew older, he 
became more nervous about teaching, and this together with declining health was probably the cause of his early retirement. In a biographical essay[4] his son-in-law Emile Ador states that his lectures were models of clarity and precision, and this is confirmed by Amé Pictet who adds that "Galissard n'était pas d'une gaiété folle". His papers are elegantly written and the arguments are clear and easy to follow. His work on atomic weights led him to consider Prout's hypothesis, and indeed this may be regarded as the motivation for his work. He was well aware that the existence of elements whose atomic weights were clearly non-integral such as chlorine seemed to disprove this hypothesis, but pointed out that an improbably large number of elements had atomic weights that were very close to whole numbers.

In his lifetime Marignac had an international reputation which was recognised by many awards and memberships of foreign academies including those of France, Sweden, Berlin, de Lincei of Rome, Moscow, and the Royal Society of London which awarded him its Davy medal in 1886 . Two years later he received the Prussian order of merit. His reputation for meticulous and precise analysis was such that results presented by Marignac were regarded as indisputable. This, coupled with his careful work of synthesis, purification, and crystallisation, establish him as a major figure in inorganic chemistry in the 19 th century.

$\mathrm{He}$ has suffered slightly from adulteration of his name in the literature: in one prominent inorganic text book he is referred to by his full name in one chapter, and as 'M.C. Marignac' in another; he generally signed 'Charles Marignac'. I have found very little written about him in English. Apart from the essay by Ador ${ }^{[4]}$ which can also be found at the beginning of the collected papers of Marignac ${ }^{5]}$ there is a long essay by Armand Buchs on Marignac's work.[6] An essay on Marignac from the point of view of the Ecole Polytechnique by Edouard Grimaux can be found on the web.

Christian Klixbüll Jørgensen was born in the city of Aalborg in Jutland on 18th April 1931. The family soon moved to Copenhagen where Jørgensen went to school and university. Throughout his life he was a prolific reader: he claimed to have read over 3000 books from the municipal libraries in Copenhagen. He rapidly showed interest in the sciences, and in chemistry and astronomy in particular. The interest in chemistry showed itself by the purchase of a home chemistry set, and, more unusually, in attempted separations of the lanthanides. His interest in astronomy led him to make the acquaintance of an amateur astronomer, Luplau-Jansen, who allowed him to use his private observatory, and lat-

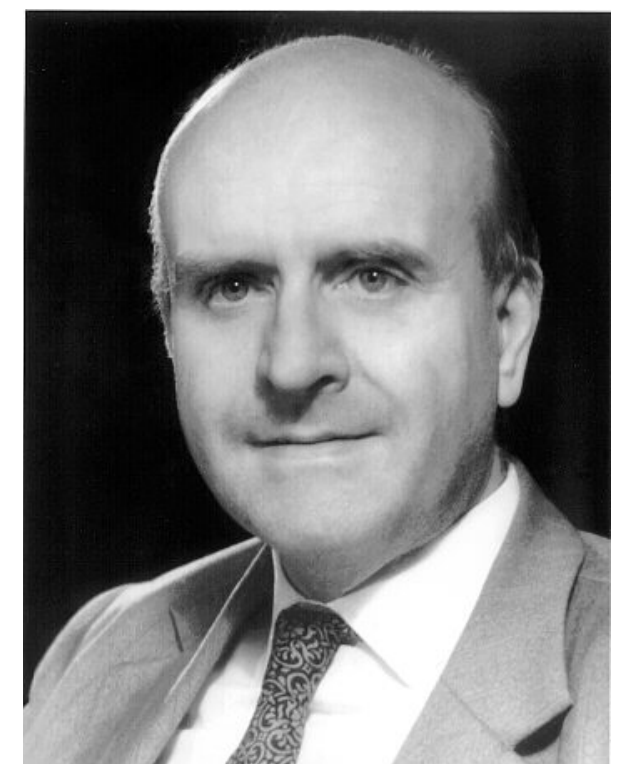

ions would be developed by Orgel, Griffith, and Tanabe and Sugano, but there was very little experimental data. Jørgensen's first major contribution was to provide the experimental basis. Between 1954 and 1957, a period when he was a research student, Jørgensen published 37 papers, most of which were single author papers. This work covered virtually all types of optical spectra of the d- and f-block elements.

Jørgensen had initially been assigned a typical Bjerrum project studying the formation of aqua ions of the transition metals in alcohol solution, but the availability of the Beckmann DU instrument made the recording of optical spectra of solutions a simple affair and he rapidly switched to this subject (it is incidentally greatly to Bjerrum's credit that he allowed this). Jørgensen's approach appears at first sight surprising: instead of concentrating on a narrow field, his early work concerned all $\mathrm{d}$ and f-block elements. This is characteristic of his tendency to take a very broad view of the subject rather than concentrating on details. He was thus able to follow the evolution from the essentially atomic spectra of the lanthanide ions (where his knowledge of spectra gained from astronomy was helpful) to the molecular spectra of the heavy transition elements. He established the general applicability of the spectrochemical series (which had been reported earlier by Tsuchida for cobalt(III) compounds) and present it as a product of a ligand factor and a characteristic value of the central metal ion which increased with metal oxidation state. His characterisation of the lanthanide spectra using the Condon-Shortley method allowed him to confirm Seaborg's actinide hypothesis that the transuranium elements were indeed f-shell elements (in the 1950s these elements were quite novel and textbooks often placed uranium in group VIA). He also established what he named the nephelauxetic effect which describes the decrease in electron repulsion parameters in metal ions arising from chemical bonding.

Jørgensen always realised the importance of his results for chemical bonding. Although the crystal field theory was based on the electrostatic field of the ligands, Jørgensen was quick to point out that the crystal field of the anion fluoride was always less than that of neutral water, and that water in turn produced a smaller field than the less polar ammonia molecule. He correctly attributed this and the nephelauxetic effect to the presence of partial covalent bonding which also explained the dependency of the crystal field splitting on the metal ion and its oxidation state. In 1957, he defended his thesis (which was in fact a habilitation) at the age of 27 . His scientific activity was reduced while in Paris, but took off again when he moved to Cyanamid. His work 
there was still concentrated on spectroscopy and completed his earlier studies, but with two important additions. He carried out a detailed study of electron transfer spectra, which had been neglected in favour of $d-d$ transitions (surprisingly since they are usually two or three orders of magnitude more intense). Again he was able to parameterise the energies of the transitions in terms of the optical electronegativity of metal and ligand. The optical electronegativity had one advantage over Pauling's values in that it varied in a sensible way as a function of the metal oxidation state. The second major contribution was the development with Claus Schäffer of the angular overlap model as a simple model for calculating ligand field splittings. This model has now established itself as the standard method for ligand field calculations.

His move to the University of Geneva marked a watershed in his career. There was now a sufficient corpus of data for complexes in solution, and the future of optical spectroscopy was in more complicated experiments on single crystals or using techniques such as magnetic circular dichroism. Jørgensen was never very attracted by complicated experimental techniques and did not follow this path, but the development of $\mathrm{X}$-ray photoelectron spectroscopy seemed to offer a new method for probing electronic structure. He worked for some years in this field but the results were disappointing: the chemical shifts were not readily related to chemical bonding, and their measurement was subject to a number of experimental difficulties. He continued to work with groups studying lanthanide spectroscopy and in particular had a long standing col- laboration with Prof. Renata Reisfeld in Jerusalem. He also published many papers on the theoretical aspects of chemical bonding, including predictions of the chemistry of quarks and superheavy elements. He remained a perceptive critic of bonding theory throughout his career, and was particularly interested by hard and soft acids and bases.

Jørgensen's personality could be overpowering. A discussion with him required a conscious effort not to be overwhelmed and to participate in the conversation which could easily become a monologue. He combined a vast breadth of knowledge with a prodigious memory. This he put to good purpose in his early work where his breadth of vision enabled him to acquire an essentially correct overview of inorganic spectroscopy. In an interesting dialogue with his supervisor Jannik Bjerrum, Bjerrum remarks that Jørgensen had extraordinary intuition, but this may also have been a consequence of his capacity to draw parallels between initially very different fields. Unfortunately his passion for the subject was also associated with a certain impatience: he could rarely be bothered to revise his first draft of a paper, often apparently written on a stream of consciousness, and many of his papers and books are very difficult to follow. If one does persist, there is much to be learned, but this opacity undoubtedly limited the impact of his papers, except among specialists in the field who often assured the diffusion of his ideas in a more accessible way. The same problem appeared in his teaching, where his courses were full of original insights for someone already familiar with the subject, but difficult for the beginning student. However, the students respected

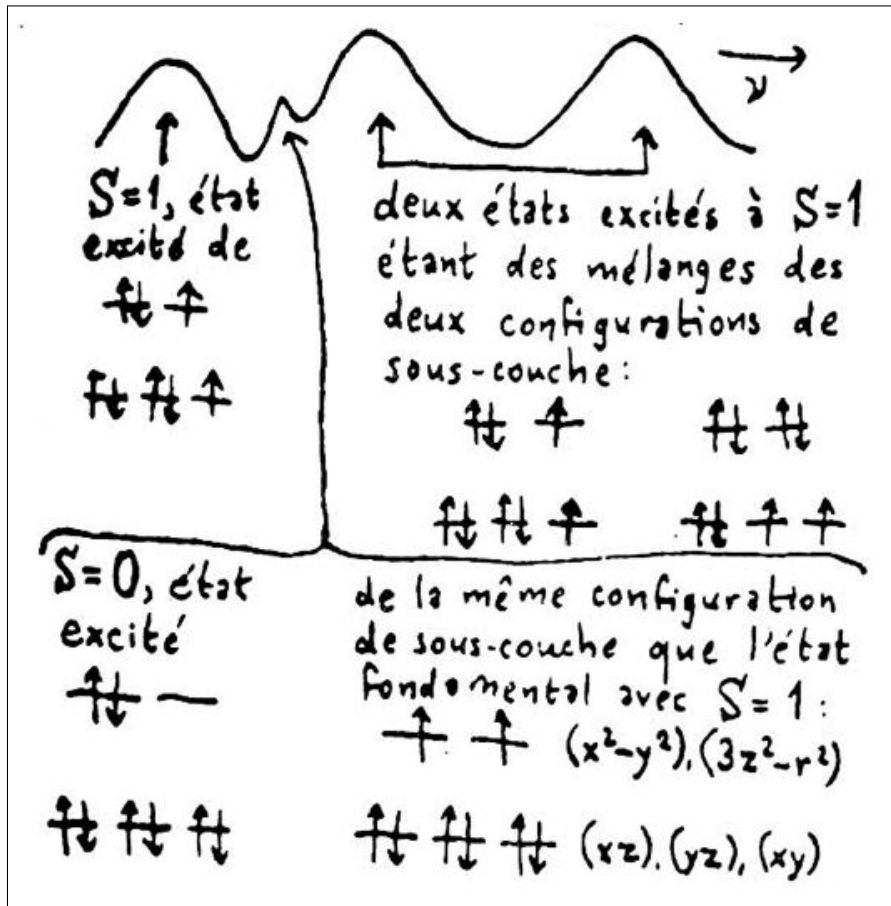

Spectroscopy before computers. Excerpt from Jørgensen's lecture notes showing the spectrum of octahedral nickel(II) his remarkable intellect, and appreciated his pleasant dry sense of humour. He was totally lacking in pomposity or arrogance, and would talk happily to anybody. Despite this he was a rather solitary character; he never established a large group at the University of Geneva, and he is the only author of a large fraction of his papers. Nonetheless it is interesting to note that his most active periods were those in which he was associated with an active research community as in Copenhagen and at Cyanamid. We may also wonder if he was not also a victim of the love of compartmentalisation which plagues modern science. He maintained his love of physics, and followed with more attention the development of elementary particle theory than the advances of organometallic chemistry.

Jørgensen was a member of the Royal Danish Academy of Sciences and Letters and received an honorary doctorate from the University of Zurich. Apart from obituaries, ${ }^{[7,8]}$ two special issues of Structure and Bonding were dedicated to him, ${ }^{[9]}$ and there is very interesting interview with Jørgensen and Jannik Bjerrum in the Journal of Chemical Education which gives a good idea of his conversation. ${ }^{[10]}$ Curiously, Jørgensen, like Marignac, showed some ambiguity in his name: his early work was published as Chr. Klixbüll Jørgensen, and he was often referred to as Klixbüll. He later tended to favour the use of Christian, but his first name was in fact Axel, although this was only used by his family.

Both Marignac and Jørgensen made important contributions to the development of inorganic chemistry. Marignac, by his painstaking experimental work of isolating and purifying the elements and their compounds and measuring atomic weights, made a major contribution which would culminate with the periodic table of Mendeleyev. Jørgensen, a hundred years later, and with a far more cerebral approach, played a vital role in developing the understanding of transition metal compounds that would so greatly change inorganic chemistry in the middle of the 20th century.

Received: September 29, 2009

[1] C. Marignac, Bibl. Univ. Archives 1858, 2, 89.

[2] C. Marignac, Bibl. Univ. Archives 1866, 25, 5.

[3] C. Marignac, Annales de Chimie 1864, 3, 5.

[4] E. Ador, Bibl. Univ. Archives des Sciences phys. et nat. 1894, 32, 5.

[5] C. Marignac, 'Oeuvres complètes de J.-C. Galissard de Marignac', Eggimann, Geneva, Masson, Paris and Friedlander, Berlin.

[6] A. Buchs, in 'Les Savants Genevois dans l'Europe Intellectuelle', Ed. J. Trembley, Editions du Journal de Genève, 1987, p. 180.

[7] A. F. Williams, Chimia 2001, 55, 472.

[8] P. Day, Coord. Chem. Rev. 2003, 238-239, 3.

[9] T. Schönherr, 'Structure and Bonding', vols 106 and 107, 2004

[10] G. B. Kauffman, J. Chem. Educ. 1985, 62, 1002. 